\title{
Socio-Economic and Cultural Causes and Effects of Increasing Divorce Rate by Women in Bangladesh: A Critical Analysis
}

\author{
Md. Manjur Hossain Patoari ${ }^{1}$ \\ ${ }^{1}$ Department of Law, International Islamic University Chittagong, Bangladesh \\ Correspondence: Md. Manjur Hossain Patoari, Assistant Professor, Department of Law, International Islamic \\ University Chittagong, Bangladesh.
}

Received: February 24, 2020

Accepted: March 18, 2020

Online Published: March 23, 2020

doi:10.20849/ajsss.v5i1.713

URL: https://doi.org/10.20849/ajsss.v5i1.713

\begin{abstract}
To create generation by maintaining family and social binding, marriage is the only legal way which is recognized by society, civilization, country and religious. All religious encourage both man and woman to marry. But this legal tie is untied by way of divorce. In consequences of divorce a bride have to return to her parental home which is not considered as respectable in the society of Bangladesh and the situation may be more difficult if parents are not alive or in poverty. Though divorce is a right of a man or a woman and he or she can legally terminate his or her conjugal life by divorce but in Bangladesh currently it has reached in such extreme level that it has become a matter of great concern. To some extent divorce relief a man or a woman from endless sufferings but most of the cases it broken dreams, hopes and aspiration of a family, causes intolerable sufferings and push their offspring future uncertainty. The prime object of this research is to trace out the connection of divorce by women and socio-economic and culture of Bangladesh. This research also attempts to find out effects of divorce on the victims, their children and also in the family and society.
\end{abstract}

Keywords: marriage, divorce, economic independence, cultural diversity, social values

\section{Introduction}

Allah has created men and women as company for one another, and so that they can protect and live in peace and tranquility according to the commandments of Allah and the directions of His Messenger. The holy Qur'an says:

"And Allah has made for you your mates of your own nature, and made for you, out of them, sons and daughters and grandchildren, and provided for you sustenance of the best". (16:72)

Islam not only encourages but also with some conditions made compulsory for Muslim men and women to marry to protect them from adultery and for the procreation of children. Islam considers marriage as one of the most virtuous and approved institutions (Doi, 1992). The Messenger of Allah ordained,

"O you young men! Whoever is able to marry should marry, for that will help him to lower his gaze and guard his modesty"(Al-Bukhari).

Hindu religious also encourages marriage. Ancient Hindu Law considers marriage as the last of the tenth sacraments. According to Hindu belief without son none can enter into heaven and only son can by taking from hell the souls of his parents place into heaven. Both in Muslim and Hindu religion a man or woman has full freedom to marry and it is one of the fundamental rights of all citizens not only in Bangladesh but also in all the countries of the world. Like marriage, divorce is also a right of all citizens of Bangladesh. Nobody can pressure a man or a woman to continue his or her conjugal life if he or she is not interested to continue his or her marital relationship.

Though in Islam, only the husband has the power to divorce and he may delegates the power of divorce to his wife. The wife can exercise divorce power only if the husband delegates this power to his wife. In original Hindu law divorce is quite impossible. No earthly thing even death can break marriage tie of a husband and wife (Uddin, \& Hossain, 2017). Even if the wife becomes prostitute or if the husband becomes a monastic, marriage tie will not be broken. But according to the existing law of Bangladesh divorce is the right of every citizen whether male or female, Muslim or Hindu or follower of any other religion. Currently in Bangladesh, a man or a woman can exercise this right without any hindrance and sometimes it is exercising on flimsy ground and no one can legally stop him or her from exercising this right. 
Divorce is a right which a man or a woman can exercise on the grounds as specified in the law. Sometimes divorce is badly needed because it protects a man or a woman from cruelty, danger, hardship, physical torture, mental pressure or from excruciating sufferings. But it has many adverse effects on family, society, bride, bride groom and mainly on the offspring. In a patriarchal society like Bangladesh where women and children are vulnerable, most of the cases divorce increases vulnerability of women and children (Bhuiya, \& Chowdhury, 1997). Many industrialized countries of the world like United States of America, Israel, Russia divorce rate is rising steadily (Haimi, \& Lerner, 2016) but due to economic, social, and cultural causes the rate of divorce by women in Bangladesh is increasing day by day and it is very alarming (Hossain, 2018). Though earlier most of the applicant of the divorce was male but in present time the situation has changed and female applicant is almost seventy percent $(70 \%)$ of the total applicant of divorce. Mental and physical torture for dowry, drug addiction and physical torture, scarcity of mutual trust, extramarital relation, not to come back for long time from abroad, addiction of Indian TV channel and facebook, impotent, degradation of social and moral values, changing of family pattern, less spending time for the family, lack of proper knowledge regarding religious norms and prohibition, high amount of dower, concealing information and self-dependent of women are the major causes of increasing divorce rate by women in Bangladesh. Divorce has many adverse effects on men and women but women and her children are affected more than men. Divorce has direct physiological, emotional, behavioral, social, occupational, financial and health effects on women and her children. It increases possibility of traumatic events in personal life. "Divorced people tend to experience increased depressive feelings over time and pass the days with great psychological changes as a result of the decline in standard of living, current economic difficulties, and reduced availability of intimate, reliable support following divorce" (Rahman, Giedraitis, \& Akhtar, 2013). Divorced women and her children are not respected in society and even parental family of the women and they are considered as extra burden by her parental family members and if the parents of the women are poor or deceased she and her children have to bear intolerable sufferings. "If child live with its mother it would suffer in terms of food intake, sickness care, nutritional status, accidental injury, and the like all the disadvantages that reduce the survival prospect of children of divorced mothers" (Bhuiya, \& Chowdhury, 1997). If child live with its father it would suffer neglect or torture of stepmother.

\section{Literature Review}

Hossain, (2018) states that physical and mental torture by the bride groom and family members of bride groom for dowry, drug addiction of husband and physical torture by the husband, involving extramarital relationship of husband, ill conduct by the husband or his family members, husband settling abroad and impotent are major causes of divorce in Bangladesh by the wife. Ghose, (2018) claimed that most of the applicants of divorce are women and the main causes of divorce by the wife are torture for dowry, extra marital relation of husband with other women or second marriage of husband, family conflict, drug addiction of husband and conflict with mother-in-law and the causes of divorce by the husband are illicit relation of wife with other men, avoid the commandment of husband and family conflict. Khanam, (2017) states that where the husband, the wife or the both are unemployed had high risk of divorce and the high income of the husband diminishes this risk and the high income of the wife increases it. Chowdhury, (2019) affirms that due to the growth of governmental sectors and other non-governmental sectors including readymade garments industry women participation in economic activities increase day by day along with their marital separation and divorce rate also increased day by day and other causes of increasing divorce are physical torture, extra marital relation, polygamy of husband, annihilate family and social bonds and values etc.

Akter, \& Begum, (2012) state that divorce is one of the most traumatic life experiences to tolerate which increase frustration, depression, anxiety, reduce physical energy and strength, work capacity, confidence level of the parties and they felt embarrassed and become hopeless, restless and misbehaved with others. Alam, Saha, Razzaque, \& Ginneken, (2001) claim that women and children are mostly affected by divorce and it increase vulnerability of women and children in Bangladesh. Aktar, (2013) states "that parents' divorce has both short-term and long-term effects on children. Some short-term effects include (1) children might feel guilty or responsible for the divorce, (2) they may become increasingly aggressive, violent and/or uncooperative, lashing out at both parents, (3) may become emotionally needy out of fear of being abandoned, (4) may lose the ability to concentrate which could then affect academic performance, and (5) may develop intense feelings of grief and loss. Although many of the effects of divorce on children are short-term after which they fade once the children has time to adjust to the new family situation and all the changes that have occurred, there are many cases where the effects may be long term. The children of divorced parents may be more likely to: (1) be less educated, (2) experience poverty and/or socio-economic disadvantage, (3) exhibit anti-social behavior as well as other behavioral problems, (4) suffer from drug and/or alcohol addiction, and (5) experience separation and/or divorce themselves". 


\section{Scenario of Divorce in Bangladesh}

Though divorce is allowed in Islam with some conditions it discourages the dissolution of a marriage-tie (Patoari, 2019) and according to original Hindu law divorce is impossible. But divorce is a right of a husband and a wife in Bangladesh and according to the existing law of the country he or she can exercise this right which nobody can prevents him or her. Though sometimes divorce becomes necessary but high rate of divorce is a matter of concern as children are directly affected by the divorce of their parents. In Bangladesh earlier divorce rate was more among illiterate and poor but currently it is increasing among all section of the people of the country especially among educated and economically solvent people. In Bangladesh last seven years divorce rate has increased thirty four percent (34\%) and highest divorce rate in Barisal 2.7 person per thousand and the lowest rate in Chattogram and Sylhet 0.6 person per thousand (Hossain, 2018). Most of the applicants of divorce are women (Ghose, 2018) and among the women applicants educated and economically self-independence women are more (Hossain, 2018).

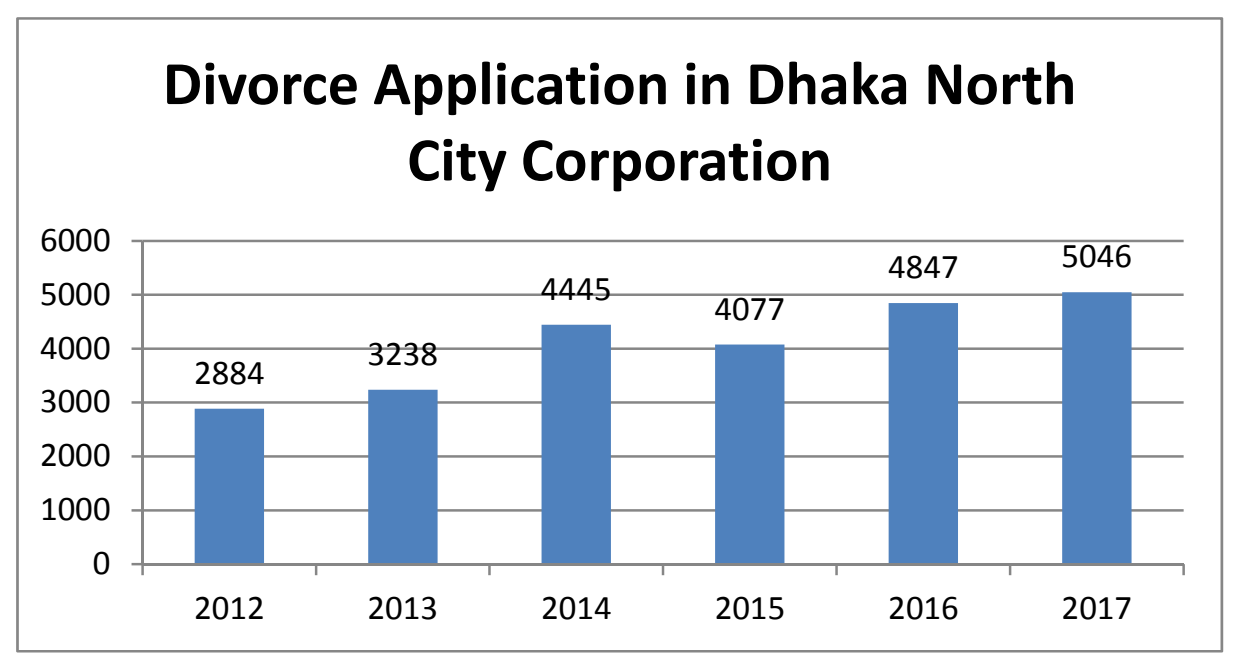

Figure 1. Divorce applications filed in the Dhaka North City Corporation from 2012 to 2017

Source: The Daily ProthomAlo (August 27, 2018)

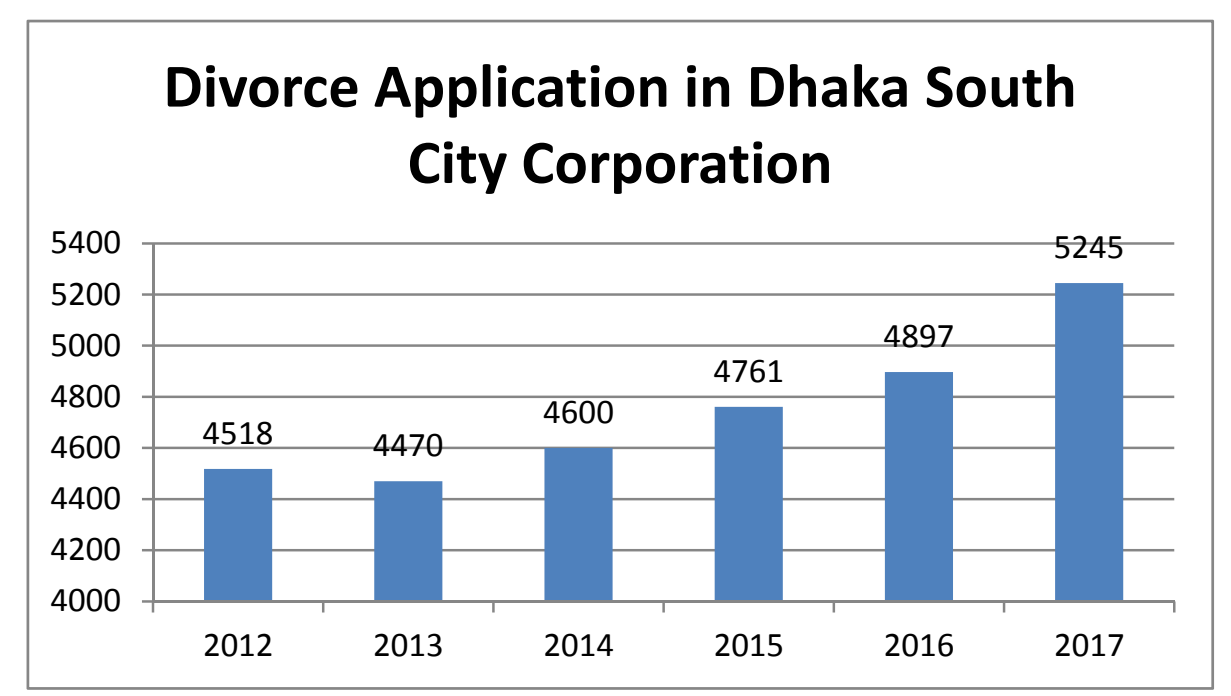

Figure 2. Divorce applications filed in the Dhaka South City Corporation from 2012 to 2017 Source: The Daily ProthomAlo(August 27, 2018) 


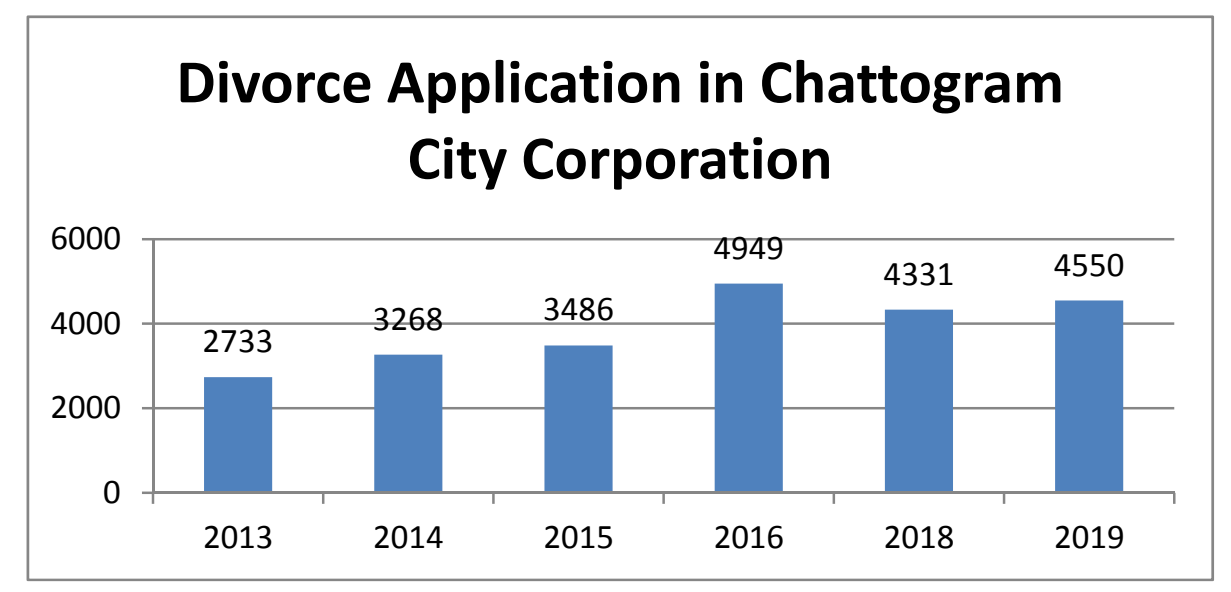

Figure 3. Divorce applications filed in the Chattogram City Corporation from 2013 to 2019

Source: The Daily Purvokon(February, 09, 2020)

Figures 1, 2 and 3 shows that divorce rate is increasing in both South and North City Corporation of Dhaka and in Chattorgam City Corporation. The divorce rate is very alarming for the country.

\section{Causes of Increasing Divorce by Women in Bangladesh}

Divorce is the only method to terminate a marriage relation legally which either party can apply on specific ground. Divorce is such a right in Bangladesh which either party himself or herself can exercise. Sometimes it is necessary for extrication of a person from sufferings or to restart life forgetting climacteric time of life with new dream, hopes and aspiration. But it has negative effect mainly on the child. The divorce rate in Bangladesh has reached in such a level which is very alarming. Though earlier most of the divorce applications were filed by the husband but currently the situation has dramatically changed and most of the divorce applications are filing by the wife. There are multiple socio-economic and cultural factors which lead to increase divorce rate in Bangladesh by women. Various causes of increasing divorce by women in Bangladesh are discussed below:

\subsection{Physical and Mental Torture for Dowry}

One of the major causes of divorce by the women in Bangladesh is physical or mental torture by the husband or husband and in-laws or other members of the husband's family for dowry to the wife. Dowry system is a social disease in Bangladesh. It is now an open secret demand of bridge groom during marriage or even after marriage in Bangladesh and it has reached in such a level that in almost eighty percent $(80 \%)$ of total marriage in Bangladesh, parents of bridge have to pay dowry (Begum, 2014). In Bangladesh especially in rural areas, parents of bridge groom arrange marriage of their son as a means to earn some money or other property having monetary value from the parents of bridge during marriage as dowry (Patoari, 2019). The practice of dowry system in Bangladesh has derived from Hindu Community and they are practicing from ancient time (Kamruzzaman, 2015) but unfortunately, gradually this evil culture has transformed into Muslim Communities and after liberation of Bangladesh it has widespread among the Muslim Communities of Bangladesh (Monsoor, 2003). Islam ensured rights, dignity, honour, respect and status of women by providing dower. She is supposed to be protected by dower but unfortunately now she has become victim of dowry (Monsoor, 2003). One class of greedy people has commercialized the marriage by practicing evil cultural of dowry.

Women are victim of various form of violation throughout the world in their daily life from domestic sphere to public sphere (Abusaleh, \& Mitra, 2016) but in Bangladesh torture for dowry is the common form of violation against women. The nature and extensity of violence against women may vary from country to country. In Bangladesh where the educational qualification and income of the husband is low, torture for dowry to the wife is more (Kamruzzaman, 2015) and different forms of torture for dowry in Bangladesh are beating, mental torture, rebuke, deprivation, insult, impute to fault, disgrace and defrauded from freedom etc. 
Table 1. Dowry related violence against (married) women in Bangladesh from January 2001- December 2018

\begin{tabular}{lllll}
\hline Year & Killed & Physical Abused & Suicide & Total \\
\hline 2018 & 71 & 69 & 2 & 142 \\
\hline 2017 & 118 & 127 & 11 & 256 \\
\hline 2016 & 107 & 94 & 5 & 206 \\
\hline 2015 & 119 & 77 & 6 & 202 \\
\hline 2014 & 123 & 103 & 11 & 237 \\
\hline 2013 & 158 & 261 & 17 & 436 \\
\hline 2012 & 273 & 535 & 14 & 822 \\
\hline 2011 & 305 & 192 & 19 & 516 \\
\hline 2010 & 235 & 122 & 22 & 379 \\
\hline 2009 & 227 & 81 & 11 & 319 \\
\hline 2008 & 188 & 71 & 10 & 269 \\
\hline 2007 & 138 & 47 & 13 & 198 \\
\hline 2006 & 243 & 64 & 8 & 315 \\
\hline 2005 & 227 & 123 & 19 & 369 \\
\hline 2004 & 166 & 78 & 11 & 255 \\
\hline 2003 & 261 & 85 & 23 & 369 \\
\hline 2002 & 192 & 90 & 28 & 309 \\
\hline 2001 & 123 & 31 & 3 & 157 \\
\hline Total & 3273 & 2250 & 233 & 5756 \\
\hline Report by & $136 a r 0 n$ & &
\end{tabular}

Source: Annual Report by Odhikaron Violence against women

Table 1 shows that number of violence against women for dowry in Bangladesh is very alarming. Hossain, (2018) and Ghose, (2018) also claimed that most of the causes of divorce by women in Bangladesh are torture by the husband or husband and in-laws or other members of the husband's family for dowry.

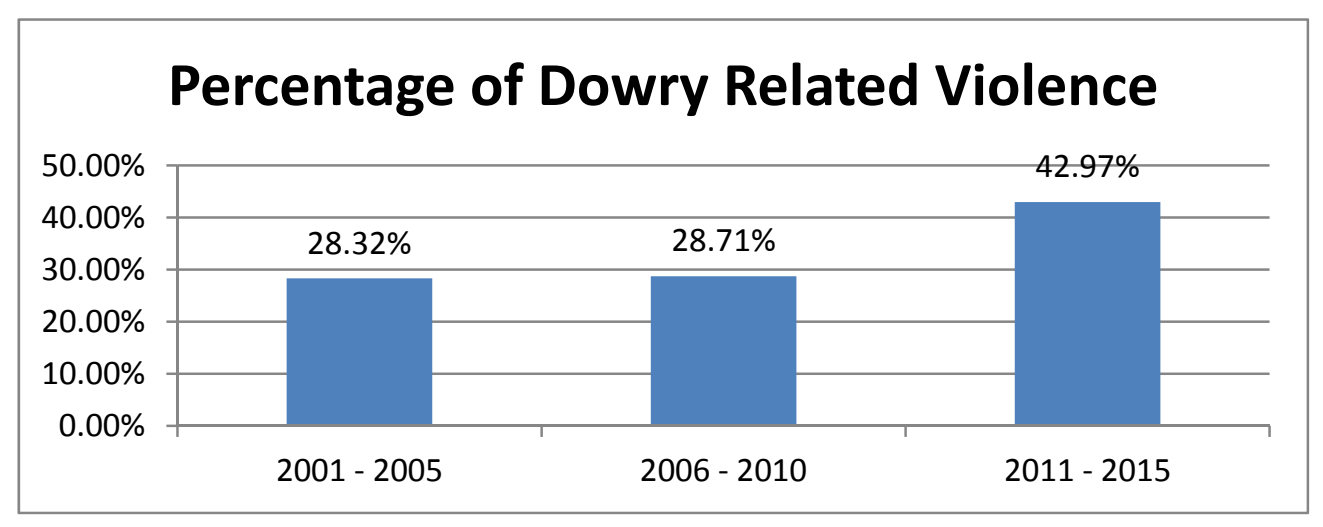

Figure 4. Percentage of dowry related violence in Bangladesh from 2001 to 2015

Source: (Abusaleh, \& Mitra, 2016)

Figure 4 shows that a considerable portion of violence against women in Bangladesh is related to dowry and it is increasing day by day. Some cases bridge parents or family have to pay dowry to the bridge groom or his family during marriage and several times after marriage. If bridge's family fails to fulfill the demand of the bridge 
groom, bridge groom himself or his family member start physical and mental torture to the bridge and sometimes due to unbearable sufferings victim commit suicide. When the victims do not have any other opportunity to relief herself from the curse of dowry, decide to divorce her husband.

\subsection{Drug Addiction of Husband and Physical Torture}

Another main cause of divorce by women in Bangladesh is drug addiction of husband and physical torture to the wife. Drug addiction in Bangladesh has become epidemic as in everywhere of the country whether in the house or street or in the workplace or parks or slums or market or even in educational institutions both rural and urban area, it is now prevalent and almost 2.5 million (twenty five lakh) people are drug addicted (Shazzad, et al., 2013). Most of the applicants of divorce in Chattogram are women and among them major portions are garments workers who divorce her husband because he is drug addicted and physically torture her for money to buy drug and the wife finding no other waybound to take decision to divorce her husband (Ghose, 2018). Beside these, as day by day women are being economically self-dependent taking decision quickly to divorce the drug addicted husband who do not take her liability rather torture her. "The spread of multiple drug use has aggravated the overall problem, personal and social days function, impairment of health, crime and other violent behavior" (Shazzad, et al., 2013). The major causes of drug addiction are neglect of parents, family disorganization, unemployment, drug trafficking becoming very easy,strife with spouse, frustration, depression, influence by the friend, rejection of love, family conflict, curiosity, psychological environment and easy availability of drugs. Available drugs are ganja, yaba (methamphetamine $30 \%$ and caffeine $70 \%$ ), phensidyl (codine, pseudoephedrine and chlorpheniramine) heroin, pethedine, cocaine, alcohol, cigarette, and dexpotent (cough syrup) etc. $93.9 \%$ of total drug addicted are male (Shazzad, et al., 2013).

Drug abuser swallows the lion share of family income because of buying drug as average cost of drugs per person from $\$ 1.9$ to $\$ 3.1$ per day or from $\$ 707$ to $\$ 1135$ per year (Shazzad, et al., 2013). Drug addiction disintegrate family tie. The addict is a threat for the family and also for the society because he loses professional and educational capacities and self-dignity (Shazzad, et al., 2013) and behaves in a hostile way with family members or involve in petty crimes to arrange money for buying drugs and even physically torture to wife or family members. As a result the life of the family members or wife sometimes is in danger and the wife getting relief herself from torture and to save her life, terminates her marriage relation by divorcing her husband.

\subsection{Extramarital Relation}

Another remarkable cause of divorce by women in Bangladesh is extramarital relation of their husband with other woman. Illicit relation provoked both husband and wife to accelerate the termination of marital relation (Rahman, Giedraitis, \& Akhtar, 2013). Marriage is the only way for getting religious, legal and social recognition of a man and a woman to live together and for procreation and legalization of their children.Sexual relation of a man and woman without subsistence of a legal marriage between them is fornication and is known as extramarital relation.Recently extramarital relation has become one of the common family problems in developing countries like Bangladesh and it is also a contributing factor for increasing percentage of divorce, violence against women, suicide and such other kinds of family discord (Jahan, et al. 2017). Bangladesh is a country where approximately ninety percent $(90 \%)$ people are Muslim who never support extramarital relation as Islam strictly prohibit extramarital affairs and the sexual relation of a man and woman is only permitted and also consider one of the good things of life as long as there subsist a valid marriage between them (Helal, 2013). Hindu, Christian and Buddhist religion also strongly criticize extramarital affair. An extramarital affair not only negatively impacts moral and psychological development but also has the chances of developing sexually transmitted diseases" (Jahan, et al. 2017). This social epidemic has direct negative impact on deceived partner and offspring, and due to this heinous act sometimes there is suicidal incidence. Deceived partner decides to terminate conjugal relation without thinking second time. Various factors are involved for extramarital relation in Bangladesh. These are discussed below:

Sex: Sex is the combination of love and passion between two persons of opposite sex. One of the main causes of extramarital affair is to fulfill sexual desire. "After a certain period, sex can become monotonous and if there is a lack of desire, passion and romance in the relationship, then it may drive the person to seek it with someone else" (Jahan, et al. 2017). Lack of self-control and dissatisfaction of sexual desire is the common cause for extramarital relation.

Married Under Pressure: Sometimes people agree marry due to pressures from family and society or sometimes consent of the party to the marriage is obtain by blackmailing by the family members, as a result there is a gap between two partners from the very beginning of their conjugal life. If this gap between husband 
and wife is continue long time, it creates emptiness among the partners and to fulfill this emptiness people search for extramarital relation.

Physical Discontent: Physical dissatisfaction is one of the prime causes of involving extramarital relation. It ultimately causes expectation gap and married female or male are very much sensitive to this issue (Jahan, et al. 2017). To fulfill sexual insatiate people involved in extramarital relation.

Financial and Career Development: Now a day's carrier development and financial establishment is the main reason of involving extramarital relation. It is one of the very pathetic reasons of extramarital relation but reality (Jahan, et al. 2017). Day by day women are involving more in various jobs especially in private sectors and most of them are very concern regarding their career advancement. Considering carrier advancement sometimes they willingly or unwillingly involve in illicit relation.

Need for Excitement: "Human instinct is quite immeasurable, diversified, and it is impossible to fathom and predict the nature and depth of any desire. A result of which is the outbreak of an extramarital affair through searching for the opportunity of removing boredom, exhaustion as well as for recreation" (Jahan, et al. 2017).

Social Media and Indian TV Channel:Due to easy availability of online dating and various social media including Facebook, Instagram, WhatsApp, imo, Messenger etc. many spouses fallen into relation outside marriage. Through these Social Medias one can express him or herself and can easily involve in relationship. Many spouses pass their leisure time by chatting Facebook, Instagram, WhatsApp, imo, Messenger etc. and sometimes involve in extramarital relation in absence of their mind. Contract in social media is the key promoter behind the rapid increase in divorce rate (Jahan, et al. 2017). Beside these, various TV channel of India available in Bangladesh is also accountable for extramarital relation in Bangladesh. Most of the Indian channels in their programs highlight extramarital relation which directly encourages extramarital relation.

Living Far from Spouse: Living far from spouse is another cause of involving extramarital relation in Bangladesh. Many people in Bangladesh live abroad for job purpose i.e. far from spouse for long time as a result he or she feel lonely and want company of another. When a man or woman lives far from spouse get huge opportunity to involve relation outside marriage. When a woman live alone for long time without her husband she remain insecure and men approach her in many ways and sometimes she herself involve extramarital relation in absence of her mind.

Family Conflict and Husband's Suspicious Nature: Family conflict directly influences women to divorce her husband. Day by day women are being educated and conscious regarding their various rights and they are not willing to continue their conjugal life in discontent environment. Frequent family conflict makes dusky the life of a woman who for getting relief herself from the situation, divorces her husband. Nowadays, most of the women want to live isolated with her husband only and are not interested to live in a joint family. Mostly, in joint family as family member is more there are many issues of conflict of a woman with her husband, mother-in-law, father- in-law, sister-in-law or brother-in-law and are not interested to sacrifice even a simple matter. As women are being involved in financial activities and financially contributing in the family, want to play dominating role in the family matter but the husband, mother-in-law, father- in-law, sister-in-law or brother-in-law cannot accept it. Day by day tolerance level of both husband and wife is decreasing and it is one of the major causes of family conflict as well as divorce. Beside these, sometimes husband's suspicious mentality is also liable for divorce by women. Continuous suspicious of the husband that the wife having an affair makes the life of the wife unhappy, foul and miserable (Nowshin, 2018) which accelerate the divorce by wife.

Education and Economic Independence of Women: Education and economic independence of woman has direct connection with divorce by women in Bangladesh. Women's participation in workplace has increased more as they are now educated more. Where the husband and wife both works, they are facing acute challenges despite having financial benefits. The rate of divorce is more among the educated husband and wife (Hossain, 2018). Most of the applicants of divorce are women who are economically independence and as they have financial independence choose they way of divorce easily (Ghose, 2018). Women's increasing independence and autonomy due to their involvement in the job market contribute towards the increasing divorce rate (Chowdhury, 2019). Earlier divorce rate was high among the poor, illiterate and unconscious people but now it is increasing in all sections of the people of the country (Islam, 2019).

Beside these some other causes of increasing divorce rate by women in Bangladesh are: impotent of the husband, not to come back of the husband from abroad for long time, disobedient, not to follow properly the direction of Islam, distemper, impersonality of the husband towards the family, changing of the family pattern, unable to give birth of child, marriage of a teenage girl with an age old person, less expending time for family, digression of 
social and moral values, concealment of information and arrange early marriage by the parents without the consent of the girl etc.

\section{Effects of Divorce}

Due to striking effects of divorce especially on children and women, increasing divorce rate by women in Bangladesh has received momentous attention. Its effects are not same for men and women but may be different. Every divorce contains the possibility of stressful events in personal life. "Divorced people tend to experience increased depressive feelings over time and pass the days with great psychological changes as a result of the decline in standard of living, current economic difficulties and reduce availability of intimate, reliable support following divorce" (Rahma, Giedraitis, \& Akhtar, 2013). Divorce affects children primarily by disrupting parent-child relationships (Amato, \& Sobolewski, 2001) and women have to suffer more than men. By divorce sometimes women get chance of positive changes of her personal life such as relief from physical and mental torture, a good career and ability to provide a better environment to children but the post-divorce consequences are very severe for women in relation to social reactions of their divorce (Rahma, Giedraitis, \& Akhtar, 2013). Effects of divorce on children, women and men are discussed below:

\subsection{Effects on Children}

Children are the primary victim of separation of their parents. Children of a broken family never get full parental love and care which is very much necessary for the physical development and mental growth of a child. Most of the cases children of a broken family live with mother and in some cases with father, if a children live with mother many cases mother cannot provide to the children healthy food, cloth, proper shelter, happy and sound environment for education due to poverty (Aktar, 2013). When a divorced mother returns to her parents' family together with her children, her parents' family members considered the children as a burden (Alam, saha, Razzaque, \& Ginnerken, 2001) and do not interested to take the liability of the children as the children is an obstacle in the way of remarriage of the mother. At the remarriage of the mother children become guardian less. If the children live with father they are deprived from mother' love, care and affection and at the remarriage of the father puts the children under the step-mother's treatment and who most of the cases do not care like her biological children (Alam, saha, Razzaque, \& Ginnerken, 2001) rather make the children's life miserable by physical and mental torturing. As a result prospective life of many children are in threaten.

Beside these, children grow up in marital conflict among parents have behavioral problems and depression (Alam, saha, Razzaque, \& Ginnerken, 2001) not only in their childhood life but also it continue in their adulthood life. Children who deprived from father's care are at high risk to involve criminal activities, drug addiction and the teenagers of divorced parents have high risk of mental disorders to drop out of school or get pregnant (Wolchik, et al. 2002). "Higher paternal involvement in school is associated with better academic function and better behavior, including higher scores, fewer absences and a positive attitude to school, compare to young children whose fathers were less involved" (Haimi, \& Lemer, 2016). Children of broken family are also at high risk of sexual and physical abuse and trafficking.

\subsection{Effects on Divorced Woman}

Though divorce sometimes creates an opportunity for the woman for positive changes of her life but most of the cases have to suffer unbearable sufferings. In the socio-economic and cultural context of Bangladesh divorced woman and her children are most vulnerable of the vulnerable in the society. A divorced woman is insecure in the society and sometimes unintentionally and in absence of her mind and sometimes for her physical demand, fallen into illegal relationship. By divorce women not only lose her husband but her identity and financial security also losses (Akter, \& Begum, 2012). In Bangladesh, a woman after the dissolution of her marriage return to her parents' family where the family members of her parents' may have sympathy for her but most of the cases do not accepted her children cordially and the society do not take her and her children positively. If the woman is not financially solvent she has to struggle more to ensure basic necessities of her children and have to fight to get maintenance of the children from her former husband. Divorced women felt uneasy, embarrassed and got no pleasure from social gathering and suffer various physiological and psychological problems (Akter, \& Begum, 2012).Physically losses energy and strength; mentally depressed, frustrated, shocked, unhappy, feels shame, losses confidence and cannot trust to anybody; behaviorally become restless, misbehaved with others and occupationally reduced capacity level and try to avoid the society.

\subsection{Effects on Divorced Men}

One of the most stressful life experiences of a man is divorce (Akter, \& Begum, 2012).Though the primary victims of divorce are women and children but men are also affected. It increases depression in the mind of the 
men and breaks dreams, hopes, aspiration and life style. Friends, relatives, colleagues and neighbors backtracks a divorced man or woman (Kalmijn, \& Unk, 2007). By divorce a man not only losses his wife but most of the cases losses children because when a family is broken children are interested to live with mother and not with father. Losing family, wife and children, a man becomes hopeless, helpless, depressed, frustrated, and his energy, strength, capacity and confidence level is reduced and suffers from various mental and physical diseases. If the children live with him it is also a cause of tension as he has to take care of the children. Most of the cases he become restless, misbehaved with others and drug addicted and for physical demand sometimes intentionally or unintentionally involve in extramarital relationship.

Besidethese it has some specific socio-economic and cultural effects in the country. It give birth some social problems like family conflict, women and children trafficking, child labour, juvenile delinquency, drop out of school, child marriage, drug addiction of children, prostitution, women and children insecurity and it create economic problems also as most of the cases women and child have to fight with poverty and food, cloth, accommodation, health and education of the children is become the main challenge of the women. It has direct effects on the culture of the country. Forgetting own customs and culture people exercise outlandish culture.

\section{Recommendation}

The rate of divorce by women in Bangladesh has reached in such a level that it has become a matter of great concern. It can be reduced effectively by taking following measures:

i. To reduce rate of divorce by women in Bangladesh dowry system should be completely abolished form the society.

ii. To diminish divorce in Bangladesh especially by women, the young generations of the country have to save from the curse of drug addiction.

iii. To save the families from broken especially by women extramarital affairs must be vanished completely. In this regard open discussion session, workshop and seminars can be arranged regarding the effects of extramarital affairs in the conjugal life.

iv. Both male and female especially educated and economically self independent women have to change their mentality.

v. Outlandish culture especially Indian and western culture have to avoid.

vi. Patriarchal mentality has to reduce in the society.

There must have mutual trust between husband and wife and husband's suspicious mentality has to abolish.

i. Joint family system has to increase in the society.

ii. Massive awareness has to create among the married persons regarding the effects of divorce on children, women and men and in this regard print and electronic media can play a vital role.

iii. Religious directions have to follow strictly.

iv. Marriage of teenage girl with an age old man without the consent of the girl has to stop.

\section{Conclusion}

In Bangladesh, on some specific grounds divorce is a right of every citizen who has entered into a valid marriage contract. Whatever state in Muslim personal law or Hindu law or other religions practice in Bangladesh, currently both men and women can exercise the right of divorce without any kind of hindrance. Divorce sometimes become necessary as by exercising this right woman gets chance of positive changes of her personal life from physical and mental torture, a good career and ability to provide a better environment to children and man gets relief from mental torture, frustration, depression and get opportunity to restart his life with new dreams, hopes and aspirations. Due to various socio-economic and cultural causes the rate of divorce in Bangladesh is increasing day by day. Earlier most of the applicants of divorce are male but presently it has dramatically changed and almost seventy percent (70\%) of total divorce applicants are women. Mental and physical torture to the women for dowry, drug addiction of husband and physical torture to the wife, scarcity of mutual trust, extramarital relation of husband or wife, not to come back of husband for long time from abroad, addiction of Indian TV channel and facebook, impotent of husband, degradation of social and moral values, changing of family pattern, less spending time by the husband for the family, lack of proper knowledge regarding religious norms and prohibition, high amount of dower, concealing information, marriage of teenage girl with age old man, ignoring the women's consent in marriage and higher education and economically self-dependent of women are the major causes of increasing divorce rate by women in Bangladesh.Divorce is the most stressful 
event in the life of a man. Though children are the primary victim of divorce but it has adverse effects on men and women also. Divorce is such an act which must have negative impact on the family and society and children, women, men and their family must be affected. Increasing divorce rate in Bangladesh is not a social and family problem rather it is an epidemic for the country which must be effectively reduced by taking proper initiatives.

\section{References}

Abusaleh, K., \& Mitra, A. (2016). Trends and Patterns of Violence Against Women in Bangladesh. Global Journal of Human-Social Science, 16(6), 28-34.

Aktar, S. (2013). Effects of Family Breakup on Children: A Study in Khulna City. Bangladesh e-Journal of Sociology, 10(1), 138-152.

Akter, M. \& Begum, R. (2012).Mental Health Problems of Women Undergoing Divorce Process. Dhaka University Journal of Biological Science, 21(2), 191-196.

Alam, N., Saha, S. K., Razzaque, A., \& Ginneken, J. K. V. (2001). The Effect of Divorce on Infant Mortality in a Remote Area of Bangladesh. Journal of Biosocial Science, 33(2), 271-278.https://doi.org/10.1017/S0021932001002711

Amato, P. R., \& Sobolewski, J. M. (2001).The Effects of Divorce and Marital Discord on Adult Children's Psychological Well-being. The American Sociological Review, 66, 900-919.

Begum, A. (2014). Dowry in Bangladesh: A Search from an International Perspective for an Effective Legal Approach to Mitigate Women's Experiences. Journal of International Women's Studies, 15(2), 249-267.

Bhuiyan, A., \& Chowdhury, M. (1997). The Effect of Divorce on Child Survival in a Rural Area of Bangladesh. Population Studies, 51(1), 57-61.

Chowdhury, A. H. (2019). Economic Independency of Women and Separation Rate in Muslim Marriages in Bangladesh. Social Science Journal, 4, 143-152.

Doi, A. R. (1992). Women in Shari'ah (Islamic Law) (4th ed.). Kula Lumpur, Malaysia: A. S. Noordeen.

Ghose, S. (2018). Per Day Fourteen Family Broken in Chattogram. The Daily ProyhomAlo.

Haimi, M., \& Lerner, A. (2016). The Impact of Parental Separation and Divorce on the Health Status of Children, and the Ways to Improve it. Journal of Clinical \& Medical Genomics, 4(1), 1-7. http://doi.org/10.4172/2472-128X.1000137

Helal, M. A. (2013). Extra Marital Affair and Family Discord: Way-out in Islam. International Journal of Islamic Thought, 2(2), 35-44.

Hossain, M. (2018). One Divorce Per Hour in Dhaka. The Daily Proyhom Alo.

Islam, E. (2019). Every Two Hours One Family Broken in the City. The Daily Purvo Kon.

Jahan, Y., Chowdhury, A. S., Rhman, S. M. A., Chowdhury, S., Khair, Z., Huq, K. A. T. M., \& Rahman, M. (2017). Factors Involving Extramarital Affairs in Bangladesh. International Journal of Community Medicine and Public Health, 4(5), 1379-1386. https://doi.org/10.18203/2394-6040.ijcmph20171506

Kalmijn, M., \& Unk, W. (2007). Regional Value Differences in Europe and the Social Consequences of Divorce: A Test of the Stigmatization Hypothesis. Social Science Research, 36, 447-468.

Kamruzzaman, M. (2015). Dowry Related Violence Against Rural Women in Bangladesh. American Journal of Psychology and Cognitive Science, 1(4), 112-116.

Khanam, M. (2017). Increasing Divorce Rate, and the Role of Economy. The Daily Observer.

Monsoor, T. (2003). Dowry Problem in Bangladesh: Legal and Socio-Cultural Perspectives. The Dhaka University Studies, 14(1), 1-16.

Nowshin, N. (2018). Understanding the Rise in Divorce in Bangladesh. The Daily Star.

Patoari, M. H. (2019). The Rights of Women in Islam and Some Misconceptions: An Analysis from Bangladesh Perspective. Beijing Law Re-view, 10(5), 1211-1224. https://doi.org/10.4236/blr.2019.105065

Rahman, M. M., Giedraitis, V. R., \& Akhtar, M. T. (2013). The Social Sanction of Divorce: Who Ultimately Pay the Social Costs of Its Adverse Effects?. Sociology and Anthropology, 1(1), 26-33. http://doi.org/10.1389/sa.2013.010103

Shazzad, M. N., Abdal, S. J., Majumder, M. S. M., Sohel, J. A., Ali, S. M. M., \& Ahmed, S. (2013). Drug 
Addiction in Bangladesh and its Effect. Medicine Today, 25(2), 84-89.

Uddin, M., \& Hossain, M. F. (2017).A Text Book on Hindu Law: Theory and Practice (2nded.). Dhaka, Bangladesh: Hira Publications.

Wolchik, S. A., Sandler, I. N., Millsap, R. E., Plummer, B. A, Greene, S. M., Anderson, E. R.,... Haine, R. A. (2002). Six-Year Follow-up of Preventive Interventions for Children of Divorce: A Randomized Controlled Trial. JAMA The Journal of the American Medical Association, 288(15), 1874-81. http://doi.org/10.1001/jama.288.15.1874

\section{Copyrights}

Copyright for this article is retained by the author(s), with first publication rights granted to the journal.

This is an open-access article distributed under the terms and conditions of the Creative Commons Attribution license (http://creativecommons.org/licenses/by/4.0/). 